\title{
Die Sporotrichosis de Beurmann und ihre Differentialdiagnose gegen Syphilis und Tuberkulose.
}

Von

\author{
Dr. Robert Stein, \\ I. Assistent der Klinik.
}

(Hiẹzu Taf. I-III und zwei Abbildungen im Texte.)

In jüngster Zeit hatte ich Gelegenheit, an der hiesigen Klinik einen typischen Fall von Sporotrichosis de Beurmann zu beobachten und genau zu untersuchen. Da in der deutschen Literatur ein solcher noch nicht existiert, halte ich eine ausführlichere Mitteilung für gerechtfertigt und glaube eine eingehendere epikritische Besprechung dadurch vermeiden zu können, daß ịch ein Resumé über das bisher auf diesem Gebiete Bekannte vorausschicke.

Gegen Ende des vorigen Jahrhunderts beschrieben amerikanische Ärzte - Schenk, Hectoen und Perkins - zwei ganz eigentümlich verlaufende Fälle von abszedierender chronischer Lymphangitis des Vorderarmes im Anschlusse an eine Verletzung am Zeigefinger. In beiden Fällen trotzten diese Abszesse jeder chirurgischen Behandlung, in beiden Fällen gelang es aus dem Eiter dieser indolenten, torpiden, kutan-subkutan gelegenen Knoten einen Sporen bildenden Fadenpilz in Reinkultur zu züchten, das Sporotrichon Schenkii. Diese Beobachtungen blieben längere Zeit unbeachtet, bis im Jahre 1903 in Paris de Beurmann und Ramond einen Patienten zur Untersuchung bekamen, bei dem eine bestimmte Diagnose nicht gestellt werden konnte. Zerstreut über den Rumpf und die Extremitäten fanden sich sehr zahlreiche (33) kleine kutan-sub- 
kutan gelegene, indolente, teils solide, teils fluktuierende Tumoren, die bis zur Größe eines Pflaumenkernes heranwuchsen. Der durch Punktion gewonnene Eiter war mikroskopisch völlig bakterienfrei. Der größte am Vorderarme entstandene Abszeß war im Februar aufgetreten und im Laufe der nächsten Wochen hatten sich am ganzen Körper die übrigen Knoten entwickelt. Anfangs dachte man an eine subkutane Cysticerken-Invasion, aber da diese Diagnose durch nichts gestützt werden konnte, wurde der Inhalt der geschlossenen Abszesse auf die gewöhnlichen Nährboden verimpft. Bei Zimmertemperatur wuchsen im Laufe einer Woche zahlreiche runde, anfangs weiße, später sich intensiv schwarz pigmentierende Kolonien, die mikroskopisch aus typischen Fadenpilzen und Sporen bestanden. Ein so hervorragender Pilzkenner wie Sabouraud war nicht imstande, den aus den geschlossenen Effloreszenzen in Reinkultur gezüchteten Pilz zu klassifizieren, er aber und de Beurmann sprachen den Verdacht aus, daß dieser Mikroorganismus vielleicht mit den pathologischen Veränderungen in ätiologischem $\mathrm{Zu}-$ sammenhange stehen könne, und daß zugleich mit diesem neuen Keim ein neues Krankheitsbild entdeckt sei.

Im Jahre 1906 beschrieben de Beurmann und Gougerot drei weitere Fälle, die dem obenerwähnten fast vollständig glichen. Wieder handelte es sich um plötzlich aufgetretene, über den Rumpf und die Extremitäten zerstreute kutan-subkutane, indolente, teils solide, teils erweichte Tumoren; wieder gelang es, den charakteristischen Fadenpilz zu isolieren. Diese Befunde gewannen natürlich durch ihre Konstanz ganz wesentlich an Bedeutung und auch bei dem größten Skeptizismus mußte man in dem de Beurmannschen Sporotrichon mehr sehen als einen harmlosen "Nosoparasiten". In demselben Jahre berichteten Brayton, Lesné und Monier-Vinard und Dor über Beobachtungen von ähnlichen, Tuberkulose oder Lues vortäuschenden, großen, vereiternden Infiltraten im kutanen Zellgewebe, aus denen sie den de $\mathrm{Be}$ urmannschen Pilz isolieren konnten. Seit dieser Zeit ist die Sporotrichosisfrage nicht mehr zur Ruhe gekommen. In vielen Sitzungen der Pariser dermatologischen Gesellschaft wurde sie diskutiert und neues Material beigebracht. In der von de Beurmann und Gougerot im 
Jạhre 1908 in der Ikonographie veröffentlichten Arbeit finden wir schon zwölf von anderen Autoren diagnostizierte und kulturell sichergestellte Sporotrichosen. Mit der Zahl der Beobachtungen wuchs das Interesse der Pariser Ärzte für diese neue Krankheit; Druelle nannte sie mit Recht „une maladie, on pourrait dire, à la mode, presque inconnue, il y a encore deux ans, passant aujourd'hui brusquement dans le domaine de la pratique journalière." In den nun folgenden Jahren durchforschten. de Beurmann und seine Mitarbeiter dieses von ihnen erschlossene Gebiet nach allen Richtungen und ihnen ist es zu danken, daß wir über die Ätiologie, Pathogenese und mikroskopische Anatomie dieses Krankheitsbildes und über die Biologie des spezifischen Erregers aufs genaueste unterrichtet sind.

Klinisch können wir zwei große Gruppen von Sporotrichosen unterscheiden, die chronischen und die akuten. Die meisten der bis jetzt bekannten Fälle hatten einen chronischen Verlauf und verursachten nur geringe oder gar keine Störung des Allgemeinbefindens. Sie ähneln bald mehr den kutanen Manifestationen der tertiär en Lues, bald mehr denen der Tuberkulose. Das sporotrichotische Gumma beginnt als kleines, derbes, indolentes, in die Cutis oder Subcutis eingelagertes Infiltrat, ist hart, elastisch, auf der Unterlage beweglich; es überragt kaum das Niveau der normalen Haut, welche nicht mit dem Knoten verwachsen ist und ibre normale Farbe zeigt. In diesem Stadium kommt die Existenz des Knotens dem Patienten noch gar nicht zu Bewubtsein und auch der untersuchende Arzt findet ihn meist erst bei genauer Palpation. Man hat das Gefühl eines ins Hypoderm eingelagerten Kirschkernes.

Innerhalb 4-6 Wochen vergrößert sich dieser Knoten; er kann eine ganz bedeutende Größe erreichen $(40-50 \mathrm{~mm}$ im Durchmesser) und verwächst mit der darüber liegenden Haut. Alsbald beginnt er im Zentrum zu erweichen und zeigt deutliche Fluktuation. Viele Effloreszenzen können auf diesem Stadium stehen bleiben, einige, bei manchen Patienten die überwiegende Mehrzahl, öffnen sich spontan nach außen und aus der Perforationsstelle entleert sich ein schleimig-seröser, gelb- 
licher Eiter. Auch die umgebende Haut ist nicht mehr normal, sie zeigt eine hellviolette unscharf begrenzte Rötung und eine geringe Infiltration. Die Fistelöffnung kann sich vergrößern, die Ränder sind unregelmäßig zackig, nicht unterminiert, nicht steil abfallend, fast reaktionslos. Auf Druck fließt der Inhalt des Abszesses aus, man blickt in eine beinahe rein granulierende Höhle, deren Wände wie ein "leerer Sack" zusammensinken, da sie einer stärkeren Infiltration entbehren. Am Orte des Durchbruches kann sich eine gelbe, wenig festhaftende Kruste bilden, die man leicht entfernen kann.

Differentialdiagnostisch legt de Beurmann bei dieser Form auf folgende Momente Gewicht: Die syphilitischen Gummen sitzen meist an den Armen oder Beinen, sie sind gewöhnlich nicht so zahlreich und entwickeln sich langsamer; sie bleiben meist klein und wachsen nicht zu großen Abszessen heran, wie manche Sporotrichome; sie exulcerieren häufiger, fast regelmäßig; das Ulcus ist zirkulär, seine derben, nicht unterminierten Ränder sind stark infiltriert, dunkelrot, oft weinrot und pigmentiert; der Geschwürsgrund ist zerklüftet, mit einer festhaftenden nekrotischen Masse oder einer schwarzgrünen Kruste bedeckt.

Der erste Typus der Syphilis ähnlichen Sporotrichosis zeigt bloß die verschiedenen Stadien der eben geschilderten Knoten. De Beurmann nenntihn: „Sporotrichose souscutanée gommeuse à foyers multiples disséminés."

Beim zweiten syphloiden Typus sind die Gummen nicht scheinbar planlos zerstreut ïber Rumpf und Extremitäten, sondern sie folgen in ihrer Anordnung dem Verlaufe der Lymphgefäße. Untereinander können sie durch bis fingerdicke, derbe, indolente, lymphangitische Stränge verbunden sein, welche man durch die Haut als drehrunde Gebilde fühlen kann. Mitunter gibt Patient mit Bestimmtheit einen Knoten als den zuerst entstandenen an, oft läßt sich sogar anemnestisch feststellen, daß an dieser Stelle eine Verletzung die Eingangspforte des Virus gebildet habe. In diesem Sinne ist die Bezeichnung eines "chancre sporotrichosique" vollständig zutreffend. Im Anschlusse an diesen Primäraffekt entstehen nun durch 
lymphogene Propagation ganz analog den Bubonuli des Ulcus molle ziemlich rasch hintereinander subkutane Abszesse, die klinisch genau denselben Verlauf haben wie die Gummen der nicht systematisierten Sporotrichose; d e B e u rman n bezeichnet diesen Typus als: forme souscutanée systématisée lymphangitique ou lymphangite sporotrichosique nodulaire gommeuse.

Im Jahre 1907 veröffentlichten de Beurmann und Gougerot eine Reihe von bakteriologisch sichergestellten Sporotrichosen, die sich ron den vorigen dadurch unterschieden, daß fast sämtliche Knoten exulceriert waren und dem Aussehen nach mehr den tuberkulösen als den luetischen Gummen ähnelten. Das exulcerierte Sporotrichom unterscheidet sich jedoch nach de Beurmann vom Skrophuloderma durch seine zentrale, oberflächliche Erweichung; der Grund des Geschwüres ist rosenrot, die Ränder etwas dicker und oft leicht ödematös, der Eiter ist schleimig und mehr homogen im Vergleiche zu dem krümeligen dünnen Sekret der Tuberkulose. Die leicht infiltrierte Zone ist breiter, der Entzündungshof violettrot. Die Entwicklung des Einzelgummas ist schneller und gesetzmäßiger als bei der Tuberkulose; ein induriertes, nicht behandeltes Infiltrat abszediert im Laufe von 4-8 Wochen. Eine schmale, geschineidige, in der Mitte etwas erhabene, kleine Narbe mit einer breiten Pigmentzone läßt eine abgelaufene Sporotrichose vermuten. Die "Sporotrichotiker" haben im Gegensatz zu manchen Tuberkulösen keine allgemeine Lymphdrüsenschwellung, es fehlen die charakteristischen Narben und Fisteln am Halse und an alten Knochenherden. Wir vermissen auf der Haut die Überreste abgelaufener tuberkulöser Prozesse in Form der unregelmäßig begrenzten, wie "gestrickt" aussehenden Narben. Eine spezifische Lungenaffektion ist nicht nachweisbar, das Allgemeinbefinden ungestört.

Die Zusammenfassung dieser Krankheitsfälle unter einem eigenen Gruppennamen - Sporotrichoses tuberculoides - ist um so mehr gerechtfertigt, weil wir an der Haut dieser Patienten noch andere Manifestationen finden können, die sich in Analogie bringen lassen mit der Tuberculosis ver- 
rucosa und mit den papulo-nekrotischen Tuberkuliden.

Einer der in der Ikonographie beschriebenen Fälle bot an seiner Stirne, dort, wo sich vermutlich die Eintrittsstelle des Virus befand, eine ovale, sechs Zentimeter breite, die ganze Stirnhöhe von der Nasenwurzel bis zur Haargrenze einnehmende Ulzeration; der Grund derselben war im Zentrum glatt und neigte zur Vernarbung; an der Peripherie fanden sich zahlreiche warzige, fleischfarbene Exkreszenzen, die von einer ganz dünnen Epidermissehichte bedeckt waren; entfernte man diese, so erwies sich das ganze darunter liegende kutane und subkutane Gewebe von Eiter durchtränkt. Die Oberfläche der geschilderten Vegetationen sezernierte eine gelblich seröse Flüssigkeit, die stellenweise zu dünnen Krusten eintrocknete. Der Rand des Ulcus war unregelmäßig, gezackt, wie ansgenagt, besonders in seinem unteren Anteile; auch hier waren die papillomatösen Wucherungen von trockenen Krusten bedeckt; ein rosa-violetter Entzündungshof umgab die Ulzeration; einige Millimeter vom Rande derselben, noch im Bereiche der Rötung, waren in die Haut kleinste, mit Schuppenkrusten bedeckte papillomatöse Effloreszenzen ausgesprengt. Diese Form der kutanen Sporotrichose ähnelt der verrucösen Hauttuberkulose außerordentlich und de Beurmann selbst schreibt: La sporotrichose verruqueuse et la plus tuberculoidedes sporotrichoses.

Die den papulo-nekrotischen Tubercaliden ähnlichen Hauteffloreszenzen der Sporotrichose bilden konische oder ovale, dunkelviolette unseharf begrenzte Erhebungen; im Zentrum tragen sie ein kleines braunes Krüstchen, welches von einem Schuppensaum umgeben ist; ein rotvioletter Entzündungshof umgrenzt den in der Haut tastbaren Knoten, der viel kleiner ist als die Reaktionszone. Auf Druck quillt unter der Kruste ein Tröpfchen schleimig serösen opaleszierenden Eiters hervor. Nach Abheben des Schorfes erscheint ein kleiner, 3-4 Millimeter tiefer Krater. Werden diese Effloreszenzen älter, so blassen sie ab und es bleiben kleine, dunkel verfärbte Närbchen inmitten eines breiten Pigmentsaumes, der dem ursprünglichen Entzündungshofe entspricht. De Beurmann nennt diese Läsionen: "Sporotrichoses dermiques nodulaires, ulóéreuses ecthymatiformes. " Ihre Lebensdauer beträgt im Durehschnitt sechs Wochen.

Gaucher und Fouquet sahen bei einem Sporotrichotiker, der nicht weniger als 86 subkutane Hautgummen autwies, am linken Handrücken eine kreisrunde Plaque von zirka fünf Zentimeter Durchmesser. Dieselbe hatte eine nur wenig infiltrierte Basis und war auf der Unterlage verschieblich. Das Zentrum schien leicht eingesunken, granulierend, in Vernarbung begriffen. An der Peripherie konnte man eine beiläufig einen Zentimeter breite, leicht erhabene Randzone erkennen, die sich 
gegen die gesunde Haut zu ganz allmählich abflachte. An der dem Ulcus zugekehrten Seite hingegen schien sie unterminiert und es ließ sich auf Druck ein dunkelgelber, dicklicher Eiter hervorpressen, in welchem durch Kultur Sporotrichonpilze nachgewiesen werden konnten. Gau cher und Fouquet betonen die große Ähnlichkeit dieser durch das Sporotrichon verursachten Hautläsion mit einer Trichophytie. Sie bezeichneten diese "superfizielle Sporotrichie" als Kerion sporotrichosique.

Da die Sporotrichon- und Trichophytonarten einander morphologisch und kulturell sehr nahe stehen, so darf es uns nicht wundern, wenn einerseits das Sporotrichon kerionähnliche Affektionen, andrerseits das Trichophyton echte Granulationsgeschwülste verursachen kann.

Das Kerion sporotrichosique und das Granuloma trichophyticum Majocehi sind der morphologische Ausdruck der biologisehen Verwandtschaft dieser beiden menschen-pathogenen Fadenpilze.

In der Mehrzahl der Fälle entwickelt sich die Sporotrichose ohne Störung des Allgemeinbefindens; sie verläuft fieberlos, ohne Abmagerung, ohne gastro-intestinale Symptome; die kutanen und subkutanen Abszesse und Infiltrate sind die einzigen klinischen Manifestationen. Doch gibt es auch Ausnahmen von dieser Regel. Es sind Fälle mit akutem Verlauf bekannt, bei denen das plötzliche Auftreten der Hautläsionen von hohen Temperatursteigerungen begleitet war, bei denen das klinische Krankheitsbild sich entwickelte wie ein akutes Exanthem. Auch der Allgemeinzustand war stark in Mitleidenschaft gezogen, der Patient magerte ab, klagte über Magendarmbeschwerden. Jede neue Gummeneruption wurde von allgemeiner Prostation und Fieber eingeleitet, man hatte völlig den Eindruck einer Bakteriämie mit Hautmetastasen.

Ebenso, wie die Sporotrichosis mitunter stürmische Reaktionen des Organismus hervorzurufen imstande ist, kann auch ausnahmsweise das "Sporotrichom" die Charaktere der chronischen Granulationsgeschwulst verlieren und die eines heißen Abszesses annehmen. Der Tumor vergrößert sich rapid, die Haut darüber ist diffus erysipelartig gerötet und ödematös, die Geschwulst schmerzt stark und öffnet sich schon frühzeitig, oft in der zweiten Woche. Die Sporotrichosen nähern sich so den bakteriellen pyämischen Infektionen. Diese letzt- 
genannten Beobachtungen sind ein weiterer Beweis für die Mannigfaltigkeit der neuen Krankheit.

Während wir über die pathologischen Veränderungen, welche die Sporotrichosis an der Haut hervorruft, genau unterrichtet sind, existieren nur spärliche Angaben über die Affektionen der Schleimhaut und der inneren Organe. De Beurmann und Gougerot, Brodier und Gastou fanden auch submucöse Abszesse im Munde oder Pharynx; Letulle sah in seinem Falle die Rachenwand eingenommen von einer großen granulierenden Wundfläche, die im Niveau der Umgebung lag und nicht, wie die meisten luetischen oder tuberkulösen Prozesse, einen bedentenden Substanzverlust zur Folge hatte. Über ulzeröse Sporotrichoseu am Auge berichtet Morax. Auch in den Muskeln und am Perioste sind bei Patienten mit bakteriologisch gesicherter Hautsporotrichose fluktuierende Knoten nachgewiesen worden. Ob endlich das Sporotrichon de Beurmanns ebenso wie die Aspergillusarten Lungenveränderungen hervorrufen kann, darüber sind die Akten noch nicht geschlossen. Wenn es auch naheliegt, bei einem Sporotrichotiker eine gleichzeitig aufgetretene Lungeninfiltration auf dieselbe Ursache zurückzuführen, so ist dennoch der Nachweis des Fadenpilzes im Sputum weder mikro. skopisch noch kulturell bis jetzt geglückt. Zu denken gibt jedenfalls die Tatsache, daß bei den in Rede stehenden Kranken trotz wiederholter Untersuchung des Auswurfs $\mathrm{k}$ e in e K oc h schen Bazillen gefunden werden konnten.

Gaucher, Louste, Abrami und Giroux berichten über Blutuntersuchung bei Sporotrichosis. Sie zählten 5,000.000 Erythrocyten und 20.000 Leukocyten, davon 5\% Eosinophile. Wäbrend eines Rezidives, das nach 6 Wochen sich zeigte, fanden sie wieder Leukocytose (17.000) mit $5 \%$ Eosinophilen.

Eine Krankheit, die klinisch so mannigfaltig sich darstellt und bald wie Lues, bald wie Tuberkulose, bald wie Trichophytie, bald wie ein heißer Abszeß aussieht, muß auch histologisch ein Mixtum compositum teils chronischer, teils akut exsudativer Gewebsveränderungen darbieten. Virchow hat seinerzeit über die Syphilis geschrieben: „Gerade bei dieser Affektion zeigt es sich, daß das morphologische Produkt keinen absoluten Wert hat; nur durch seine Entwicklung und Rückbildung, durch seine Geschichte, durch sein Leben bekommt es seine Bedeutung." In gleichem Maße gilt dies von der Sporotrichosis.

De Beurmann und seine Mitarbeiter haben sämtliche von ihnen beschriebenen klinischen Varietäten histologis ch genau untersucht. Wir geben in folgendem eine kurze Zusammenfassung und verweisen im übrigen auf die mit zahlreichen $\mathrm{Ab}$ bildungen versehenen zitierten Arbeiten. 
An der typischen Hautaffektion der Sporotrichosis, dem kutansubkutan gelegenen Gumma, können wir mikroskopisch drei Zonen unterscheiden. In der Peripherie finden wir eine intensive entzündliche Reaktion des Bindegewebes. Das Infiltrat ist in der Umgebung der Gefäße am stärksten, es umgibt die kleinen Arterien und Venen in Form mantelförmiger Scheiden und setzt sich aus jungen Bindegewebszellen, Plasmazellen und spärlichen Mastzellen zusammen. Die Gefäße sind im Zustande der "Panvasculitis". Die Maschen des Bindegewebes sind auseinander gedrängt, mitunter noch in Form eines feinsten, aus kollagenen Fasern bestehenden Netzes zwischen den Zellen nachzuweisen. Weiter gegen das Zentrum zu treten Anhäufungen von epithelioden und Riesenzellen auf, die nach Art „tuberkuloider Follikel" gruppiert sind. In diesen Follikeln sehen wir Ansammingen polynukleärer Leukocyten (microabcès centrofolliculaire) oder roter Blutkörperchen (microhématome centrofolliculaire). Je mehr wir uns der Erweichungsstelle nähern, umso dichter liegen die polynukleären neutrophilen Zellen und Makrophagen; einzelne derselben zeigen zwar schlechte Kernfärbung oder Kernzerfall, jedoch niemals wird die Nekrose diffus, dicht neben nekrotischen finden wir vollständig normal sich färbende Elemente. Das Sporotrichom ist also syphilisähnlich in seiner Peripherie, tuber$\mathrm{kuloseähnlich} \mathrm{in} \mathrm{seiner} \mathrm{Mitte,} \mathrm{ekthymaähnlich} \mathrm{in} \mathrm{seinem} \mathrm{Zentrum.}$ Gerade die merkwürdige Mischung dieser drei Reaktionsformen ist charakteristisch für diese neue Granulationsgeschwulst.

Bei der Syphilis ist der Entzündungsprozeß diffuser, weniger umschrieben; kleine aberrierende Gummen an den Gefäßen sehen wir noch in scheinbar gesundem Gewebe. Die Nekrose im Zentrum beginnt an verschiedenen Stellen. Die mittlere Zone bildet ein dichtes Plasmom, aus Plasmazellen und Lymphocyten zusammengesetzt. Intensive Entzündung und Thrombosierung der Gefäße und ihrer Wandungen sind viel häufiger als bei der Sporotrichose. Epithelioide und Riesenzellen liegen regellos zerstreut, polynukleäre Leukocyten sehen wir in geringer Menge, der ganze Knoten besitzt keine fibröse Kapsel, sondern grenzt sich nur unscharf gegen die intakte Umgebung ab.

Gegenüber der Tuberkulose unterscheidet sich das Sporotrichom mikxoskopisch durch folgende. Eigenschaften: 1. Die Tuberkulose neigt zur Verkäsung, die Sporotrichose zur Abszeßbildung. 2. Das tuberkulöse Infiltrat ist viel einfacher, viel ärmer an Zellformen als das sporotrichotische. 3. Die Nekrose ist im Tuberkel kompakt, im Sporotrichom liegen nekrotische Zellen dicht untermengt mit normal tingiblen. 4. Die Gefäßalteration ist bei der Tuberkulose viel intensiver, und 5. Tendenz zur Ausbreitung bei der Tuberkulose, zur Abkapselung bei der Sporotrichose.

Ist es schon schwer, die Sporotrichose mikroskopisch von Lues oder Tuberkulose abzugrenzen, so kann ihre Differenzierung gegen manche Formen chronischer, nicht spezifischer Eiterungen im kutanen und subkutanen Zellgewebe fast unmöglich werden. Abgesehen von don klinischen 
Erscheinungen der letztgenannten Affektionen - schleichender Beginn, langsames Wachstum, Schmerzlosigkeit, keinerlei Stōrung des Allgemeinzustandes, torpides Fortschreiten - gleichen sie auch in ihrem histologischen Verhaiten - Mikroabszeß im Zentrum, epithelioide Zellen in der Mittelzone, Plasmazellen und Lymphocyten an der Peripherie - oft völlig den Sporotrichosen.

Die beiden besten Kenner der Sporotrichose, de Beurmann und Gougerot, schließen ihre letzte Arbeit mit folgenden Worten: „Die Syphilis, die Tuberkulose, die Sporotrichose und die chronischen Eiterungen sind zwar vollständig unterschieden durch ihre Ätiologie, aber sie zeigen deutliche Übergänge in ihren histologischen Reaktionsprodukten. Die Glieder dieser Kette hängen innig mit einander zusammen und der Sporotrichose gebührt der Platz zwischen Tuberkulose und den chronischen Kokkeninfektionen."

Bis jetzt ist es beim Menschen noch nicht gelungen, in den pathologisch reränderten Geweben das Sporotrichon mikroskopisch einwandsfrei nachzuweisen. Ram ond berichtet allerdings, die "globulösen Formen" des Parasiten in Riesenzellen gesehen zu haben, aber de Beurmann selbst äußert sich sehr vorsichtig. Diese Formen tingieren sich intensiv mit Kernfarbstoffen und sind daher schwer von zerfallenen, pyknotischen Kernen zu unterscheiden.

Auch im Eiter, der aus zahlreichen neutrophilen polynukleären Leukocyten und Makrophagen sich zusammensetzt, ist die Verwechslung mit Kerntrümmern und metachromatischen Blutkörperchenresten naheliegend. Da man jedoch bei der experimentellen Sporotrichose des Meerschweinchens und der Ratte sowohl im Eiter als auch im Schnitte diese ,formes globuleuses" ganz deutlich erkennen kann, so läßt sich vermuten, daß die genannten ähnlichen Einschlüsse in den menschlichen Zellen mit ihnen identisch sind. Sie sind ovale Gebilde, die von einer dünnen ungefärbten Membran umgeben werden. Sie färben sich nach Gram und mit dem Unnaschen Methylenblau.

Vollständig sicher und relativ einfach aber können wir die Anwesenheit der Sporotrichonpilze durch das Kulturverfahren erkennen. Sabouraud vergleicht deshalb die Sporotrichome mit den tiefen Trichophytien, in 
welchen wir auch oft vergebens mikroskopisch den spezifischen Erreger suchen, dessen Gegenwart in zahlreichen Exemplaren die Züchtung aufdeckt.

Das Sporotrichon de Beurmannsisteinsporenbildender Fadenpilz. ${ }^{1}$ ) Wenn man ein geschlossenes, deutlich fluktuierendes Sporotrichom unter sterilen Kautelen punktiert und den so gewonnenen Eiter auf Maltoseagar, Glykoseagar oder Glyzerinkartoffel aussät, so sind die ersten Kolonien beiläufig nach 6 bis 12 Tagen sichtbar. Es gibt Sporotrichonstämme, die auch bei Brutofentemperatur gedeihen, jedoch in der Mehrzahl der Fälle wächst dieser Pilz bei Zimmertemperatur viel besser und üppiger als bei $37^{\circ}$. Die Röhrchen sollen nicht mit Gummikappen verschlossen werden, denn Luftzutritt begünstigt die Entwicklung. Anfangs sind die Kolonien kleinste, matte, weiße Pünktchen, die sich in den folgenden Tagen mit einem zwei bis drei Millimeter breiten Strablenkranz umgeben. Weiterbin sinkt das Zentrum ein, die anfangs kugelförmige, glatte Oberfläche beginnt sich radiär zu fälteln, die Aureole wird breiter, die Flächenausdehnung nimmt rasch zu. Nach zwei bis drei Wochen ändert sich der Farbenton, die Kolonie wird in der Mitte dunkler, fast schwarz und je älter sie ist, um so auffälliger wird diese Schwärzung. Die Intensität derselben nimmt vom Mittelpunkte gegen die Peripherie hin ab. Am Rande bildet sich eine ganz schmale, wie aus feinstem weißen Staube bestehende Zone. Je trockener der Nährboden und je älter die Kultur ist, um so deutlicher ist diese Zone zu erkennen. Einen Monat alte Kulturen gleichen dünnen elastischen, zierlich gewulsteten, schwer zerreißlichen Häutchen, eingesäumt von einem breiten schwarzen Hofe, dessen radiäre Streifung mit der Zeit an Deutlichkeit verliert. Überimpit man eine solche Kolonie, so wachsen die Keime in der zweiten Generation rascher und üppiger als in der ersten. Derjenige Nährboden, auf welchem das Sporotrichon am besten gedeiht, das "milieu de choix", ist Glykoseagar. (Nach Sabouraud: Aqua $100^{\circ} 0$; Pepton 1.0-2.0; Glykose 3.0-4.0; Agar 1:5-2.0.) Jedoch auch auf anderen Medien läßt es sich züchten, nur ist die Art des Wachstums etwas verändert. Als zweites "milieu de choix“ bezeichnen de Be-

1) Das Sporotrichon Schenkii unterscheidet sich von ihm augenscheinlich nur durch schnelleres und leichteres Wachstum. 
urmann und Gougerot die Glyzerinkarotte. Am dritten Tage schon schießen kleinste weiße Pünktchen auf, am sechsten konfluieren sie, am zehnten beginnen sie sich zu falteln und am fünfzehnten werden sie schwarz. Auf Glykosebouillon bildet sich zuerst an der Oberfäche ein glattes weißes Häutchen, welches später untersinkt. Ein zweites wächst an der Oberfläche und deckt nach dem Untergehen das erstentstandene. So sammelt sich dann am Boden des Röhrchens eine Reihe gewulsteter Membranen, die Bouillon bleibt stets klar.

Ferner gelangen Kulturen auf Stroh, Blättern, Gräsern, Mehl, Früchten etc. Auch auf Raupen, toten und lebenden Insekten wächst der Pilz als Saprophyt. Impft man Kaninchen oder Meerschweinchen mit einer Kulturaufschwemmung, so kann man mitunter beobachten, daß an den Haaren in der Umgebung der Impfstelle, welche von ausfließenden Tröpfchen benetzt wurden, ein weißer aus Pilzfäden bestehender Flaum sich entwickelt, der jedoch niemals pathologische Veränderungen verursacht. Diese Beobachtungen lassen ein saprophytisches Dasein dieses Pilzes vermuten und geben vielleicht die Erklärung dafür, wie sich der Mensch mit dieser Krankheit infiziert. Eine Analogie bilden hiezu die Befunde Buschkes, der mit scheinbar harmlosen Hefearten eine Blastomycetenseptikämie experimentell erzeugen konnte.

In Deckglasausstrichen erkennen wir, daß die einzelnen Kolonien aus einem Gewirr von Myzelfäden und zahlreichen Sporen bestehen. Die Fäden sind lange, gerade oder leicht gekrümmt, bald verzweigt, bald mit einander anastomosierend. Sie sind ungefähr $2 \mu$ breit, stellenweise spindelförmig aufgetrieben, besonders an den Teilungsstellen. Sie besitzen eine zarte Membran und sind durch senkrechte Scheidewände in Abschnitte von etwa 25-40 $\mu$ Länge gegliedert. Ihr Protoplasma ist granuliert. Diese Granulationen färben sich intensiv mit Metbylenblau und Hämatoxylin, sind ferner stark grampositiv; de Beurmann hält sie für einen „diffusen Kern".

Die Sporen sind $5-6 \mu$ lang, $5-4 u$ breit, ovoid, sehr zahlreich, besitzen eine braune Eigenfarbe, und enthalten eine chromatinähnliche Substanz.

Sie umgeben die einzelnen Fäden mantelförmig, oder sind zu kleinen traubenförmigen Gruppen angeordnet. Der eine Pol ist zu einem feinen Stiele ausgezogen, mit welchem die Spore an dem Zentralfaden haftet. Charakteristisch für das Sporotrichon ist also ein naus septierten Fädenbestehendes Mycelium, mitteilseinzelstehenden, teils gruppierten, gestielten Sporen". Das flaumige Aussehen alter Kulturen ist verursacht durch eine Entfärbung der Konidien, die schrumpfen und einen Teil der chromatischen Substanz verlieren.

Das Pigment ist in den Sporen enthalten, jedoch mikroskopisch nicht in Form korpuskulärer Elemente nachweisbar; es ist unlöslich in Alkohol, Äther, Aceton, Chloroform und Mineralsäuren. Es ist eisenfrei und gibt weder die Ferrozyankalium- noch die Schwefelammoniumreaktion. Der Zuckerreichtum des Nährbodens, die Aus. 
trocknung und das Licht beschleunigen sein Auftreten; jedoch keiner dieser Faktoren ist absolut notwendig. Im Beginne der Verfärbung durch Formol abgetötete Kolonien bräunen sich trotzdem in den folgenden Tagen noch tiefer.

Die Sporen ertragen eine Temperatur von $45^{\circ}$ eine Stunde lang, eine solche von $53^{\circ} 15$ Minuten lang, ohne ihre Lebensfähigkeit einznbüßen, scheinen jedoch empfindlich gegen antiseptische Lösungen zu sein.

Der aus dem Eiter gezüchtete Fadenpilz ist kein zufälliger Nosoparasit, sondern tatsächlich der Erreger dieser Krankheit, denn:

1. Können wir mit Reinkulturen an Versuchstieren Veränderungen erzeugen, die denen beim Menschen anatomisch gleichen.

2. In den experimentell entstandenen Sporotrichomen ist das Sporotrichon mikroskopisch und kulturell nachzuweisen.

3. Auch aus dem kreisenden Blute der infizierten Menschen und Versuchstiere ist es in einigen Fällen geglückt, den Parasiten zu isolieren.

4. Das Serum der Sporotrichosekranken Menschen und Versuchstiere agglutiniert die Sporen dieses Pilzes und gibt bei hochgradiger Durchseuchung des Organismus mit dem Myzelextrakt die Komplementfixation.

Die Sporotrichosis ist experimentell auf junge Meerschweinchen, Mäuse, Ratten, Katzen und Affen übertragen worden. Das empfänglichste Versuchstier ist die Ratte. Der sicherste Infektionsmodus ist die subkutane oder intraperitoneale Injektion, doch auch die Fütte$\mathbf{r u n g}$ junger Meerschweinchen mit infizierter Milch hatte ein positives Ergebnis.

Bei den künstlich erzeugten Sporotrichosen müssen wir zwei Formen unterscheiden, deren Differenzen einerseits durch die Virulenz des Stammes, andererseits durch die Disposition des Impftieres bedingt sind. Nach wiederholter Tierpassage hochvirulente Keime können bei Ratten innerhalb 14 Tagen den Tod zur Folge haben. Wir finden bei der Sektion nirgends Granulome, hingegen eine intensive Degeneration der Parenchyme, in erster Linie der Niere, ferner gelingt der Nachweis der Pilze im Blute (Sporotrichämie) und im Urine (Sporotrichurie).

Die chronische Sporotrichosis läßt sich ebenfalls im Tierversuch reproduzieren. De Beurmann berichtet über eine sporotrichotische Ratte, die zahlreiche kutan-subkutane Abszesse aufwies und konnte eine 
Katze demonstrieren, die von mehr als sechzig Hautgummen bedeckt war. Der letztgenannte Fall nähert sich schon sehr dem Krankheitsverlaufe beim Menschen, denn die Intensität der Hauteruption steht in krassem Gegensatze zur geringen Alteration der inneren Organe. In den Gewebsläsionen der Ratte sehen wir die Parasiten mit einwandsfreier Deutlichkeit. Sowohl im Infiltrate selbst als auch im Eiter sind sie in Menge vorhanden. Sie haben eine längsovale Form $(3-5 \mu$ lang, $2-3 \mu$ breit) oder ähneln kugeligen oder keulenförmigen Gebilden. Sie sind basophil, fein granuliert, von einer zarten ungefärbten Membran umgeben.

Die mikroskopische Anatomie der tierischen Sporotrichome deckt sich in den Hauptzügen mit der der menschlichen. Nur grenzen sich die experimentellen Infektionsgeschwïlste unscharf gegen die normale Umgebung ab und enthalten entsprechend ihrem rascheren Entstehen weniger epithelioide und Riesenzellen. Im Zentrum bildet sich gleichfalls zuerst ein MikroabszeB, bestehend aus polynukleären Leukocyten und Makrophagen. Einzelne der letzteren sind deutlich nekrotisch, andere wieder, trotz ihres reichen Gehaltes an eingeschlossenen Parasiten, in ihrer Struktur scheinbar unverändert.

Die Retrokultur des Pilzes gelingt leicht, ja er wächst sogar schneller als aus dem menschlichen Eiter.

Die Empfindlichkeit der Ratte gegen das Sporotrichon ist zu diagnostischen Zwecken benützt worden. Im allgemeinen reagiert nämlich dieses Versuchstier zuerst mit einer visceralen Sporotrichose, bevor Hauterscheinungen auftreten. Bei der männlichen Ratte wird auch der Hoden ergriffen und da man wegen der exponierten Lage dieses Organes die Schwellung und Abszedierung deutlich verfolgen kann, so läßt sich diese frühzeitige Epididymitis und Orchitis genau so wie beim Rotz zur Identifizierung des Erregers verwenden. Allerdings ist die Kultivierung dieser pathogenen Fadenpilze so leicht und das Aussehen der einzelnen Kolonie so charakteristisch, daß wir die experimentelle Orchitis nur in den seltensten Fällen zur Diagnose werden heranziehen müssen.

Impft man eine männliche Ratte intraperitoneal mit einer Kulturaufschwemmung oder mit reichlich Parasiten führendem Eiter, so schwellen die beiden Hoden ungefähr am 15. Tage an. Sie nehmen alsbald an Volumen zu, sind gespannt und hindern das Tier am Laufen. Die Infiltrate vereitern, die Abszesse bleiben entweder geschlossen, oder der Inhalt entleert sich nach Usurierung der darüberziehenden Skrotalhaut durch eine Fistel. Die Autopsie ergibt in diesem Stadium zahlreiche 
Granulationen aut dem Peritoneum parietale und auf der Serosa des Darmes. Die stärksten Veränderungen finden sich an Samenstrang, Nebenhoden und Hoden. Sämtliche Hüllen des vas deferens sind derb infiltriert, die Epididymis ist in eine harte, von zahlreichen Knoten durchsetzte Masse umgewandelt, die Scheiden des Hodens verdickt und mit einander verwachsen, das ganze Organ in eine Schale chronisch entzündlicher Membranen eingebettet. Zerstreut in Parenchyme des Hodens und Nebenhodens finden wir teils einzelstehende, teils konfluierende, zentral nekrotische oder vereiterte Herde. Der anatomische Befund erinnert so sehr an die menschliche Genitaltuberkalose, daß de Beurmann die Vermutang ausspricht, es könnten vielleıcht manche Fälle scheinbar kryptogenitischer Nebenhodentuberkuloseätiologisch auf Sporotrich os e zurückzuführen sein.

Mikroskopisch erweisen sich diese Hodensporotrichome aus chronischem Granulationsgewebe zusammengesetzt; sie enthalten in ihrem Zentrum den typischen Mikroabszeß und die "formes globuleuses" des Parasiten in reicher Menge.

Endlich müssen wir noch erwähnen, dab die experimentelle Sporotrichose auf die Nachkommenschaft übertragbar ist; de Beurmann berichtet über eine hereditär sporotrichotische Ratte, die eine diffuse Gummeneruption an der Haut darbot.

Aber ebenso wie der Mensch, können auch Tiere spontan an Sporotrichose erkranken; Lutz und Splendore beschrieben eine durch Sporotrichon de Beurmann bedingte Rattenepidemie. Fonteynot und Carongean beobachteten in Madagaskar ein sporotrichotisches Maultier und Gougerot und Caraven berichten über drei aus einem Wurfe stammende, durch diesen Keim infizierte Hündehen.

Ein weiteres Argument für die Pathogenität der de Beurmannschen Pilze ist der gelungene Nachweis im kreisenden Blute.

Widal und Weil entnabmen einem Sporotrichotiker mit 97 Hautgummen $20 \mathrm{~cm}^{3}$ Blut aus der Vene und verteilten es in $500 \mathrm{~cm}^{3}$ Glykosebouillon. Nach sechs Tagen waren die ersten Kulturen an der Oberfläche in Form von Myzelien sichtbar.

Wenn man einen dicht gewachsenen Sporotrichonrasen mit der Platinöse von seinem Nährboden abhebt, in Kochsalzlösung zerreibt und diese Aufschwemmung durch ein einfaches Filter filtriert, so findet man im Fjltrate suspendiert die Sporen 
dieses Pilzes, während die Mycelfäden zurückgehalten werden. Diese Sporensuspension kann zur Prüfung der Agglutinati ons fähigkeit des Serums benützt werden.

Die rerwendeten Kulturen sollen mindestens einen Monat alt sein, da erst um diese Zeit die Sporulation in vollem Gange ist. Widal und Abrami, Sicard und Descomps stellten bei ihren Patienten einen Agglutinationstiter 1:800 resp. $1: 500$ fest.

Gaucher, Louste, Abrami und Giroux beobachteten ferner einen Patienten, der bald nach der ersten Gummeneruption ein multiples gleichfalls gummöses Hautrezidiv darbot. Knapp vor dem Auftreten des Rezidivs stieg plötzlich die Agglutinationsfähigkeit des Serums von 1:800 auf $1: 1500$. Dieser plötzliche Anstieg läßt vielleicht auf einen Durchbruch eines sporotrichotischen Herdes in die Blutbahn mit folgender "Sporotrichämie" schließen.

Zwei Fälle de Beurmanns agglutinierten noch ein Jahr nach ihrer Genesung bis zu 1:80, resp. 1:60.

Abrami fand ferner im Serum seines Sporotrichotikers einen spezifischen Amboceptor, der mit dem Mycelextrakt des Pilzes Komplementfixation ergab.

Die biologische Verwandtschaft, welche zwischen diesem neuen pathogenen Keim und dem Aktinomyces besteht, kommt darin zum Ausdruck, daß erstens auch die Seren Aktinomykotischer bis zu einem gewissen Grade Sporen des Sporotrichon agglutinieren, zweitens Mycelextrakte von Aktinomyces mit dem Serum Sporotrichotischer Komplementfixation bedingen.

Da es de Beurmann und seinen Mitarbeitern gelungen ist, das Sporotrichon auf Gräsern, Blättern, Gemüse, Tierhaaren zu züchten, so können wir wohl annehmen, daß dieser Pilz in der Natur als Saprophyt vorkommt. Jene Sporotrichosen, die im Anschlusse an eine Verletzung auftreten, sind wohl nur als eine kutane Einimpfung des Keimes zu deuten. Auch der mitzuteilende Fall gehört in diese Gruppe. Doch scheint es durchaus nicht notwendig zu sein, daß die Eintrittspforte des Parasiten pathologische Veränderungen aufweist. Wir kennen disseminierte Hautsporotrichosen ohne "sichtbaren Primäraffekt ${ }^{\text {. }}$. 
De Beurmann hat bei einem bereits genesenen Patienten Sporotrichon auf der scheinbar gesunden Schleimbaut der Mandeln gefunden und bei neugeborenen Meerschweinchen Fütterungssporotrichose erzeugt. Diese Befunde machen es wahrscheinlich, daß auch der Mensch vom Verdauungstrakt aus infizierbar ist.

Endlich käme als Infektionsquelle vielleicht auch die spontane Tiersporotrichose in Betracht.

Das souveräne Mittel gegen diese neue Krankheit ist das Jodkalium. Wir verabreichen es in steigenden Dosen, von 2.0 täglich angefangen. Die bestehenden Infiltrate involvieren sich ziemlich prompt. Reichlich sezernierende perforierte Sporotrichome behandelt de Beurmann mit feuchten Umschlägen von: Jodi puri 1.0, Kali jodati $10^{\circ} 0$, Aqu. dest. 500.0. Trotzdem das Jodkali einen ganz evidenten Einfluß auf die Heilung der Sporotrichose hat, so tötet es den Parasiten selbst $\mathrm{nich}$ t. In Glykosebouillon, der bis zu $10 \%$ Jodkali zugesetzt wurde, wachsen die Keime zwar etwas langsamer, aber noch immer üppig. Durch systematische Vorbehandlung mit Jodkaliinjektionen kann man die Ratten vor einer experimentellen Sporotrichose nicht schützen. Wir kennen Fälle, bei denen auf Jodkalidarreichung sämtliche Hautgummen zurückgingen und, trotz Fortsetzung dieser Medikation, ein gummöses Rezidiv auftrat, welches allerdings rasch wieder abheilte.

Die nicht zu verkennende therapeutische Wirkung der Jodsalze beruht also nicht etwa auf einer direkten Bakterizidie; sie scheinen vielmehr nur die Resorption der pathologischen Krankheitsprodukte $\mathrm{zu}$ beschleunigen und so die endgültige Heilung zu veranlassen.

Anamnese unseres Falles.

Vater des Patienten starb mit 65 Jahren an einem Schlaganfall, die Mutter im 47. Lebensjahre an einem Lungenleiden; ein Bruder erlag mit 22 Jahren einer Blutvergiftung im Anschlusse an eine Verletzung. Aus der ersten Ehe der Mutter stammen vier Halbgeschwister, zwei Brüder und zwei Schwestern, die alle leben und gesund sind. Patient ist unverheiratet.

An Kinderkrankheiten weif er sich nicht zu erinnern. Patient ist am Bielersee geboren. Er war immer in der Schweiz mit Ausnahme eines $1 \frac{1}{2}$ jährigen Aufenthaltes in London und eines halbjährigen Auf- 
enthaltes in Cannes (vor vielen Jahren). Einmal litt er an einer langdauernden Gonorrhoe.

Im November 1893 bemerkte Patient am Penis eine kleine Ulzeration, die dorsal im Sulcus coronarius gelegen und zirka acht Tage nach dem letzten Coitus aufgetreten war. Ein Apotheker erklärte dieses Geschwür als einen "Schanker" und gab ihm ein Pulver zum Anfstreuen. Drüsen in inguine sollen weder gleichzeitig noch späterhin aufgetreten sein. Nach dreiwöchentlicher Behandlung durch den Apotheker konsultierte Patient einen Arzt.

Während er in Behandlung dieses Arztes stand, der Pillen und Bäder verordnete, soll ein aus roten Flecken bestehender Ausschlag am Rumpfe aufgetreten sein. Ob dieses Exanthem juckte oder nicht, weiß sich Patient nicht zu erinnern. Das Ulcus heilte bald, das Exanthem schwand, Patient ging nicht mehr zum Arzt und stellte den Gebrauch der Pillen ein. Im Frühjahr 1894 verließ er Cannes und kehrte in die Schweiz zurück. Weitere luesverdächtige Erscheinungen traten nicht auf.

Im Winter 1904 erkrankte er in Zürich ziemlich plötzlich mit Husten, Fieber und Stechen in der rechten Seite. Er mußte zehn Tage lang im Spital liegen und wurde mit Umschlägen behandelt. Ein Wärter bezeichnete dieses Leiden angeblich als Brustfellentzündnng.

Im Sommer 1906 akquirierte Patient im Anschlnsse an eine Verletzung mit einem rostigen Nagel eine Phlegmone am rechten Fuße, die inzidiert werden mußte. 1907 wurde ein vereitertes Hühnerauge an einer Zehe derselben Extremităt im Basler Spital ausgekratzt.

Im Okt. 1908 nahm Patient eine Stelle als Casserolier in einem Hotel in Montreux an. Als solcher mußte er die Speisereste enthaltenden Kochund Eßgeschiere reinigen und oft stundenlang im schmutzigen Spülwasser mit entblößten Händen und Unterarmen hantieren. Zu Neujahr 1909 verbrannte er sich in der Küche am rechten Vorderarme. Die kleine Brandwunde beachtete er nicht weiter, verband sie auch nicht, sondern setzte sie unbekũmmert dem Einfluß des durch Speisereste verunreinigten Spülwassers aus. Die vernachlässigte Wunde begann zu eitern und wandelte sich allmählich in einen fast gar nicht schmerzenden Abszeß um. Auch in der Umgebung entstanden im Laufe der nächsten Wochen nacheinander einige zuerst derbe, dann aber erweichende, vollständig schmerzlose Knoten, deren einer bis za $\mathrm{Nußgröße} \mathrm{heranwuchs} \mathrm{und} \mathrm{von} \mathrm{einem} \mathrm{Arzte}$ inzidiert wurde. Weiterhin bemerkte er ein gleiches, hartes und ganz indolentes Infiltrat im rechten Sulcus bicipitalis, welches ebenfalls im Zentrum allmählich vereiterte. Ganz analoge Effloreszenzen zeigten sich in Form kutan-subkutaner Knoten im Epigastrium, unter dem Rippenbogen rechts und links, am Rücken und am linken Oberschenkel. Alle hatten den gleichen Verlauf. Anfänglich bildete sich ein kleines, hartes, rundes Infiltrat, welches zu Kirschen- bis Nußgröbe heranwachs und keinerlei Beschwerden verursachte. Die darüber ziehende Hautdecke verdünnte sich, an einzelnen Stellen kam es zu spontaner Perforation and aus einer kaum merkbaren Öffnung entleerte sich dünnflüssiger, gelblich- 
seröser Eiter. Keiner der Abszesse war schmerzhaft, viele deutlich durch die normale Haut hindurch tastbare Knoten kamen dem Patienten gar nicht zu Bewußtsein, erst die genaue Untersuchung deckte ihre Existenz auf.

\section{Resumé:}

Ein 44jähriger Mann, der im Jahre 1894 eine auf Lues, im Jahre 1904 eine auf Tuberkulose verdächtige Erkrankung durchgemacht hatte, verbrennt sich zu Neujahr 1909 am rechten Vorderarme. Die kleine vernachlässigte Brandwunde wandelt sich in einen indolenten Abszeß um. In der Folgezeit entstehen zuerst an derselben Extremität, dann disseminiert am Rumpfe und linken Oberschenkel kutan-subkutane, indolente Knoten, von denen einige erweichen, andere nach erfolgter Erweichung perforieren.

Status praesens: 44jähriger Mann, mittelgroß, kräftig, gut genährt, Pannicu] us adiposus reichlich vorhanden, Gesichtsfarbe rot, Allgemeinbefinden ungestört. Patient klagt nicht über Schmerzen; die Temperatur vollständig normal. Arteria radialis verläuft gerade, in ihrer Wandung nicht verdickt, Pulswelle normal hoch, Spannung nicht erhöht, Puls rhythmisch, äqual, Frequenz 72. Respiration ruhig, kostoabdominal. Die Inspektion der Mund- und Rachenorgane ergibt (Dr. Valentin): Tonsillen stark atrophisch, Rachenschleimhaut trocken (Pharyngitis sicca). Keine sichtbaren Schleimhautverwölbungen, die auf submuköse Abszesse oder Infiltrate bindeuten; in der Nasenhöhle fehlt rechterseits das vordere Drittel der unteren Muschel; mittlere Muschel normal; Deviatio septi nach rechts. Links ist die untere Muschel sehr klein, die mittlere normal. Schleimhaut der Nase ist blaß, atrophisch, Kehlkopf normal.

Keine vergrößerten Lymphdrüsen am Halse und Nacken.

Thorax ist gut gewölbt, beide Thoraxbälften beteiligen sich in vollkommen gleicher Weise an der Respiration; über beiden Lungenspitzen normaler Perkussionsschall; über der ganzen übrigen Lunge nirgends eine Dämpfung nachzuweisen.

Lungengrenzen: Rechts in der Mamill.-Lin. am unt. Rand d. VI. R.; in der mittl. Axillar.-Lin. am unt. Rand d. VIII. R.; hinten zwischen dem X. u. XI. Brustwirbeldorn. Links in der mittl. Axillar.-Lin. am unt. Rand d. VIII. R. Hinten ebenso wie rechts. Die Lungengrenzen sind überall prompt um 3 Querfingerbreite respirator. verschieblich. Die Auskultation ergibt normales vesikuläres Atemgeräusch über der ganzen Lunge, nirgends Rasselgeräusche, Giemen oder Pfeifen, nirgends abgeschwächtes Atmen.

Herzspitzenstoß im V. Interkostalr, ca. ein Querfinger breit innerh. d. Mamill.-Lin. Herzgrenzen nach oben III. Interkostalraum, nach links Spitzenstoß, nach rechts linker Sternalrand. Herztöne rein, keine Geräusche, keine abnormen Accentuationen, 
Abdomen etwas über dem Niveau des Thorax, normal konfiguriert, nirgends druckempfindlich, ïberall normaler tympan. Perkussionsschall, keine Fluktuation, keine Flankendämpfung.

L eber und $\mathrm{Mil}$ z weder palpatorisch noch perkutorisch vergrößert.

Urin: strohgelb, sauer, frei von Eiweiß und Zucker, spurenweise Indikan.

Blut: Hämoglobin (S a hli) $80 \%$, Erythrocyten 5,400.000, Leukocyten 5.600.

Im gefärbten Blutpräparate keine patholog. Formen. Eosinophile: $2 \%$, Basophile $1 / 2 \%$. Neutrophile $55 \%$. Große Lymphocyten $16 \%$. Kleine Lymphocyten $17 \%$, Übergangszellen $10 \%$.

Sputu m: stark schleimig, fadenziehend. Mikr.: wenig Leukocyten, viele Epithelien, reichlich Gram-positive Diplokokken in Ketten und Haufen, Gram negative Stäbchen, keinerlei auf Fadenpilze oder deren Sporen verdächtige Elemente.

Stuh l: Normal gefärbt und geformt, fäkulent, alkalisch reagierend, keine Beimengungen von Schleim, Blut oder Eiter. Mikroskop: Keine unverdanten Mukkelfasern oder Fett; Bakteriengemenge, bestehend aus zahlreichen Gram-negativen Bazillen und vereinzelten großen Gram-positiven Kokken, keine Fadenpilze.

Status nervosus: Sensorium frei, Intelligenz entsprechend, Stimmung normal, Gedächtnis gut, keine Sprachstörungen.

A ugenbefund (Dr. Pflüger): Muskelbewegungen beider Augen völlig normal, keine Ptosis, Konjunktiven reizlos, Cornea und vordere Kammer normal, Pupille rechts ziemlich eng, links etwas weiter, Reaktion a u Licht beiderseits fast gänzlich erloschen (nur mit Binokularlupe schwache Reaktion sichtbar). Reaktion auf Akkommodation beiderseits prompt. Tiefe Medien klar, Fundus normal.

Gang bei offenen Augen sicher, bei geschlossenen Augen ebenfalls. Stehen bei offenen Augen fest, bei geschlossenen kein Rhombergsches Phänomen.

Motilität sämtlicher willkürlicher Muskeln normal. Keine Störungen der Schmerzempfindung, Berührungsempfindung oder des Temperatursinnes. Lokalisation für Schmerz und Berührung normal, desgleichen die aktive und passive Bewegungsvorstellung. Weder bei offenen noch geschlossenen Augen Ataxie. deutlich.

Fußsohlenreflex plantar, Bauchdeckenreflex und Kremasterreflex

Tricepssehnenreflex sehr schwach, Patellarsehnenreflex und Achillessehnenreflex bei wiederholten Untersuchungen nicht auslösbar. Keine Mastdarmstörungen.

Mitunter angeblich im Schlafe unbewußte Urinentleerung. Im wachen Zustande keine Inkontinenz, keine Störung im Ablaufe oder in der Wahrnehmung des Miktionsaktes. Keine Retention von Urin.

Keine Anbaltspunkte für lanzinierende Schmerzen, Gürtelgefühl oder gastrische Krisen. 


\section{Hautstatus:}

Die einzelnen Sporotrichome sind in folgender Weise verteilt:

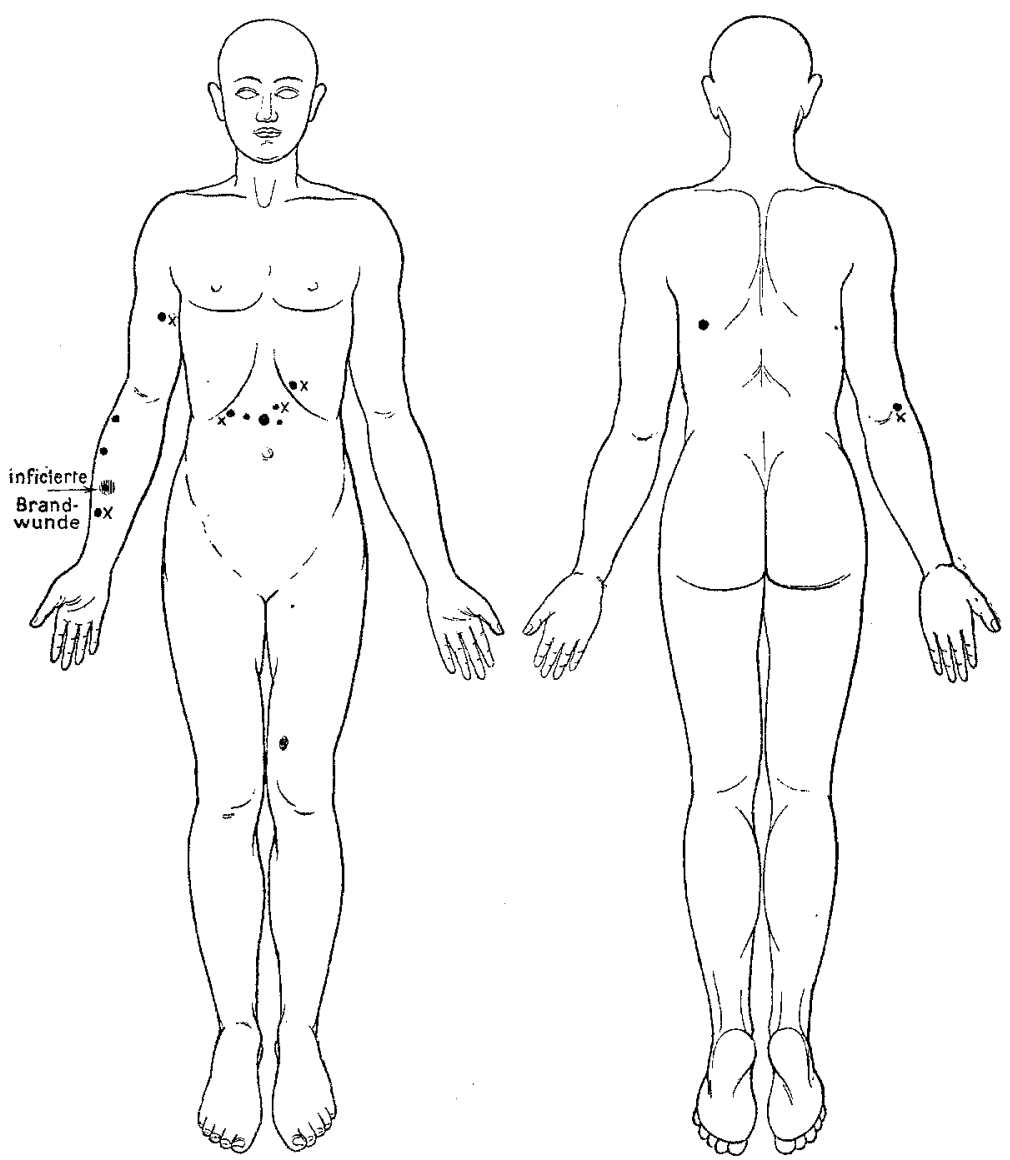

Sechs mit einem $\times$ bezeichnete geschlossene Abszesse enthielten das Sporotrichon in Reinkultur.

Die auffälligsten Hautveränderungen finden wir im mittleren und oberen Drittel des rechten Vorderarmes an der Radialseite. Wir sehen in der Längsachse der Extremität gelegen nebeneinander vier kirschen- bis nußgroße, kutan und subkutan gelegene blauviolette Knoten, die vollständig indolent und auf 
der Unterlage frei verschieblich sind. Untereinander sind diese Infiltrate durch derbe, indolente, bis kleinfingerdicke lymphangitische Stränge verbunden. Drei dieser Knoten sind perforiert, der vierte, am meisten distal gelegene fluktuiert deutlich. Die Perforationsöffnungen sind fast vollkommen realstionslos, mit einer gelben leicht abhebbaren Kruste bedeckt. Nach dem Ablösen derselben blickt man in eine granulierende Wundhöhle. Drückt man auf den ganz wenig infiltrierten Rand des Abszesses, so entleert sich aus der Fistelöffnung noch etwas dickflüssiger, gelblich gefärbter Eiter. Ein nußgroßer, im Zentrum erweichter, indolenter Knoten in der Mitte des rechten Sulcus bicipitalis, kutan-subkutan gelegen, blauviolett gefärbt. Die Haut ist darüber verdünnt. Eine ganz gleiche Effloreszenz finden wir auf dem Rücken unterhalb des linken Schulterblattes. In der Mitte zwischen Nabel und Processus xiphoideus ein blaurotes subkutan-kutanes Infiltrat, in der Mitte exulceriert, mit einer gelblich grünen Kruste bedeckt; nach dem Abheben derselben sieht man ein ca. bohnengroßes Ulcus mit unregelmäßigem, gezacktem Rande und reinem, granulierenden Grunde. In der Umgebung desselben tühlt man rechts und links unter dem Rippenbogen fünf indolente, frei auf der Unterlage verschiebliche, mit der Haut verwachsene bohnengroße Knoten, die deutlich fluktuieren. Die Haut ist über diesen Effloreszenzen etwas gespannt, von normalem Aussehen.

An der Innenseite des linken Oberschenkels in unteren Drittel ist eine in der Tiefe gelegene, taubeneigroße, deutlich fluktuierende Geschwulst zu tasten, die weder mit ihrer Unterlage noch mit der darüber ziehenden normal aussehenden Haut verwachsen ist. In den Ellenbeugen, Axillen und Leisten $\mathrm{k}$ e in e vergrößerten oder druckempfindlichen Lymphdrüsen zu fühlen.

Im Sulcus coronarius und an den übrigen Teilen des Penis keine Narbe zu sehen. Die rechte kleine Zehe verkrüppelt, der proximale Phalangealknochen fehlend.

Eine lineare Narbe nach Inzision einer Phlegmone am rechten Fußrücken.

Klinische Diagnose: Multiple kutan-subkutane, teils geschlossene, teils perforierte chronische Hautabszesse. Indolente Lymphangitis 
suppurativa des rechten Vorderarmes. Tabes incipiens?

Wir suchten nun uns zunächst darüber klar zu werden, auf welche Ursache diese multiplen, im Verlaufe weniger Wochen entstandenen Gummen zurückgeführt werden könnten. Differentialdiagnostisch waren 1. Tuberkulose, 2. Syphilis und 3. Sporotrichosis de Beurmann in Betracht zu ziehen.

Abgesehen von der oben erwähnten im Jahre 1906 überstandenen Lungenaffektion, deren tuberkulöse Ätiologie höchst nnsicher war, sprach nichts für eine tuberkulöse Infektion. Patient war sehr kräftig, eher etwas fett, litt nie an Nachtschweißen, hatte keine Lymphdrüsenschwellungen, keine rezenten oder alten Knochenaffektionen mit Fistelbildung; an beiden Lungen erhoben wir einen normalen Perkussions- und Auskultationsbefund, nirgends fanden wir Residuen einer Pleuritis. Die Pirquetsche Kutanreaktion war zwar positiv, doch die subkutane Tuberkulininjektion $(1 \cdot 0 \mathrm{mg})$ hatte weder Störung des Allgemeinbefindens noch eine Temperatursteigerung zur Folge. Auch das plötzliche Entstehen so zahlreicher, über den ganzen Körper zerstreuter Hautabszesse bei einem Mann jenseits des vierzigsten Lebensjahres war für uns ein weiterer Grund, Tuberkulose mit großer Wahrscheinlichkeit auszuschließen.

Näher lag es unzweifelhaft die Affektion für tertiär-luetisch anzusehen. Anamnestisch hatte Patient vor nunmehr 16 Jahren eine venerische Infektion durchgemacht, die auf Syphilis entschieden verdächtig war, denn ein Arzt verordnete damals Pillen und ein Exanthem soll im Verlaufe der Behandlung aufgetreten sein. Allerdings fehlte in den folgenden Jahren trotz der vollständig ungenügenden Therapie jedes Rezidiv. Ferner ist das förmlich explosive Aufschießen multipler über den Rumpf und die Extremitäten disseminierter Knoten mit dem gewohnten klinischen Bilde einer Tertiärlues nicht recht vereinbar. Auch die Einzeleffloreszenz war nicht für Gumma syphil. charakteristisch. Die subkutanen Knoten waren sehr klein und zeigten trotzdem schon deutlich Fluktuation. Die perforierten Infiltrate am Vorderarm hatten eine auffallend wenig indurierte Wandung, die Fistelöffnung war fast ganz reaktionslos, nicht ulzeriert, nicht scharf 
begrenzt, die Wundhöhle granulierte üppig und sezernierte einen dickflüssigen, nur wenig gummiartigen Eiter.

Die Abszesse am rechten Vorderarme verband untereinander ein bis kleinfingerdicker, durch die Haut sichtbarer, indolenter Lymphstrang. Und zu allen diesen klinischen Atypien kamen noch zwei Momente, die uns bewogen, die Diagnose Lues für unwahrscheinlich zu halten, erstens die bestimmte Angabe des Patienten, daß die Krankheit im Anschlusse an eine infizierte Brandwundeaufgetreten sei und zweitens der negative Ausfall der zweimal angestellten Wassermannschen Reaktion.

Trotzdem wir bisher noch nie einen Fall von Sporotrichosis beobachtet hatten, hielt mein Chef auf Grund der oben angeführten Befunde schon klinisch diese Diagnose für die wahrscheinlichste - vor allem, weil die Kombination lymphangitischer und disseminierter gummaartiger Herde sowohl für Lues als für Tuberkulose außergewöhnlich schien.

Am 19. Februar punktierten wir zwei geschlossene $A b-$ szesse am rechten Arme. Der eine war durch einen lymphangitischen Strang mit der infizierten, eitrig belegten Brandwunde verbunden, der andere lag im Sulcus bicipitalis und stand in keinem sichtbaren Zusammenhang mit den Knoten des Vorderarmes. Wir impften mit dem dickflüssigen, homogenen Eiter einige Maltose-Agarröhrchen und Glyzerinkartoffeln. Bei Brutofentemperatur blieben die Nährböden steril. Hingegen gingen in allen bei Zimmertemperatur gehaltenen Eprouvetten zahlreiche Kolonien auf; ungefähr am 10. Tage sahen wir kleinste, matte, weiße Pünktchen, die alsbald einen deutlichen Strahlenkranz an der Peripherie erkennen ließen, am 14. Tage dunkler wurden und nach etwa drei Wochen eine tiefschwarze Färbung annahmen.

Drei kutan subkutan gelegene, bohnengroße, deutlich fluktuierende Infiltrate unter dem Rippenbogen, deren Eiter unter sterilen Kautelen am 2. März entnommen und auf Maltoseund Glykose-Agar und auf Glyzerin-Kartoffel ausgesät wurde, ergaben denselben Befund: Sterilität bei Brutofentemperatur, vereinzelte, isolierte, am 10. Tage sichtbare Kolonien bei Zimmertemperatur, welche 
sich ebenfalls mit einer radiär gestreiften Aureole umgaben und im Laufe ron 20 Tagen intensiv schwarz wurden.

Die einzelne Kolonie setzte sich aus typischen Fadenpilzen und zahlreichen den Mycelien aufsitzenden gestielten Sporen zusammen. Das makroskopische Aussehen stimmte vollständig mit einer seit Monaten an unserer Klinik vorrätig gehaltenen Pariser Testkultur des de Beurmannschen Sporotrichon uiberein, das mikroskopische Bild glich der de Beurmannschen Beschreibung und den Reproduktionen seiner ersten Arbeit. Unser Sporotrichon teilte mit den de Beurmannschen Stämmen folgende Eigenschaften: Es wuchs nur bei Zimmertemperatur, allerdings etwas langsam, die Pigmentbildung trat am Ende der zweiten Woche auf, die Glykose-Bouillon blieb klar, nur am Boden sammelte sich ein dichtes Konvolut von Fäden und Sporen. Am stärksten pigmentierten sich die auf Maltose-Agar und Glyzerinkartoffel gewachsenen Keime, die auf Glykose- oder reinem Traubenzuckeragar gezüchteten blieben am längsten weiß. Vielleicht ist aber daran die chemische Zusammensetzung unserer Glykose schuld. Das Licht hatte keinen Einflub auf die Schnelligkeit des Wachstums und Lichtabschluß verzögerte das Auftreten des Pigmentes nur um ein geringes. Das Pigment war mikroskopisch nicht an irgendwelche geformte Körnchen gebunden, sondern die Sporen der schwarzen Kolonien zeigten im Gegensatz zu denen der noch weißen einen ganz diffusen braunen Farbenton.

Ferner enthielten die ly $\mathrm{m} p \mathrm{~h}$ og e $\mathrm{n}$ en Abszesse bedeutend mehr Keime als die durch $\mathrm{h}$ äm a $\mathrm{t}$ o g e n e Infektion entstandenen Knoten im Epigastrium.

In den nach Gram gefärbten Deckglaspräparaten des Eiters fanden wir neben zahlreichen polynukleären Leukocyten vereinzelte Gram-positive Gebilde, die wir jedoch bei unserer geringen Erfahrung nicht als Pilzelemente ansprechen wollen.

Aus dem kreisenden Blute gelang es uns nicht, den Parasiten zu isolieren. Mit diesem Befunde stimmt die Fieberlosigkeit unseres Patienten überein, ferner fehlte L e uk ocytose und Eosinophilie.

Ungefähr in der 10. Krankheitswoche (Mitte März) untersuchten wir zweimal den Agglutinations-Titer unseres Patienten 
gegen eine Sporenaufschwemmung seines eigenen Sporotrichon. Eine vier Wochen alte, dicht gewachsene, schwarze Glyzerinkartoffel-Kultur wurde vom Nährboden abgelöst, in Kochsalzlösung zerrieben und filtriert. Das Serum agglutinierte die so erhaltene Sporensuspension an beiden Tagen bis $\mathrm{zu}$ einer Verdünnung 1:600 deutlich, 1:800 schwach, 1 : 900 gar nicht. Kontrollsera ergaben keine Agglutination.

Ich versuchte eine Kutanreaktion, sowohl mit Trichophytin (nach der Angabe Blochs) als auch mit einem "Sporotrichin*. Das Trichophytin wurde uns von Herrn Bloch freundlichst überlassen - die Reaktion war negativ. Das "Sporotrichin" stellte ich mir her, indem ich eine sechs Wochen alte Glykose-Bouillonkultur vier Stunden lang im Schüttelapparate schütteln ließ und dann durch ein Bakterienfilter filtrierte. Auch hier trat eine Cutireaktion nicht auf. Möglicherweise war die Kultur noch nicht alt genug. Weitere Schlüsse aus diesen isolierten negativen Befunden zu ziehen, liegt mir natürlich fern. Erfolglos impften wir ferner mit unserem Sporotrichin Patienten, die an tiefen Trichophytien litten und auf Trichophytin deutlich reagiert hatten.

Herr Rothe hatte die Freundlichkeit, das Serum auf Komplementfixation zu prüfen und zwar mit einem Antigen, das durch Verreiben der Pilzrasen in Kochsalzlösung und folgendes Schütteln hergestellt war. Auch hier war das Resultat negativ (im Gegensatz zu dem oben erwähnten positiven Ergebnisse Abramis bei einem Falle, der auch andere Blutveränderungen - Eosinophilie, Leukocytose - darbot).

Zur histologischen Untersuchung exzidierten wir einen ungefähr kirschkerngroßen Knoten von der Außenseite des rechten Ellenbogens, welcher förmlich unter unseren Augen entstanden war. Als Patient das erstemal untersucht wurde, war an dieser Stelle im subkutanen Zellgewebe eine kaum tastbare, kugelige Resistenz zu erkennen, die im Laufe ron 6 Wochen zu der eben erwähnten Größe heranwuchs. Die darüberziehende Haut schien normal und an den undeutlich fluktuierenden Tumor fixiert. Am 29./III. schnitt ich die kleine Geschwulst mit einem Teil des umgebenden gesunden Gewebes heraus. Auf dem Durch- 
schnitt sah man eingelagert in die Cutis eine kirschkerngroße, weiche, gelbbraune Masse; der mit einem sterilen Messer abgestreifte Gewebssaft wurde auf Maltoseagar überimpft und ergab nach 10 Tagen spärliche aber ganz typische Kolonien des Sporotrichon.

Das Präparat fixierte ich in steigendem Alkohol und färbte es nach den gewohnten Methoden. Die Epidermis und ihre Anhangsgebilde waren mikroskopisch intakt. An der Grenze zwischen Cutis und Subcutis liegt ein außerordentlich zellreiches Granulom, welches Zellstränge zwischen die Fettläppchen und die Züge des kutanen Bindegewebes entsendet und dieselben auseinanderdrängt. An der Peripherie sieht man auch innerhalb der Infiltrationsmasse kollagene Fasern, die in dem eigentlichen Granulom vollständig fehlen, wohl aber sind in den Randpartien des letzteren noch Reste von Fettgewebe zu konstatieren. Den Hauptbestandteil des Granuloms bilden epitheloide Zellen, in welche regellos kleinere und größere Häufchen von Eiterkörperchen eingelagert sind, die de Beurmannschen "Mikro$a b s z e s s e^{u}$. Außerdem finden sich bald disseminiert, zwischen den epithelioiden Zellen, bald in kleinen Streifchen und Gruppen typische Plasmazellen, zum großen Teil einkernig, manche mit 2 und 3 Kernen; endlich auch spärliche Langhanssche Riesenzellen ohne charakteristische Lagerung. Der Tumor ist in seinen mittleren Anteilen von oft ziemlich weiten Kapillaren durchzogen, gegen den Rand zu sehen wir auch etwas größere Gefäße, deren Wand mehr oder minder entzündlich verändert ist. Nekrosen sind nirgends vorbanden.

Dieses Granulom ist also nicht typisch wie ein Gumma gebaut und nicht typisch wie ein Tuberkel, sondern es gleicht in der Buntheit seiner Zusammensetzung einem Mittelding zwischen diesen beiden Granulationsgeschwülsten. Tuberkuloseähnlich wird es durch seinen Gehalt an Riesen- und epithelioiden Zellen, syphilis ähnlich durch die vielen Gefäbe und Plasmazellen. Nur die multiplen Mikroabszesse lassen ein "Sporotrichom" vermuten. An Gram-Weig ert-Präparaten gelingt es zwar leicht, in diesen Fibrin nachzuweisen, aber Pilzelemente, deren Anwesenheit 
doch durch den Kulturbefund sichergestellt wurde, fanden wir nicht.

Endlich versuchten wir noch mit unserem Stamme die die für das Sporotrichon de Beurmann charakteristische Hodenaffektiom zu erzengen. Zwei männliche Ratten wurden mit je $2 \mathrm{~cm}^{3}$ einer vier Wochen alten Kulturaufschwemmung intraperitoneal infiziert. Nach 14 Tagen schwoll bei beiden Impftieren der Hodensack an, die bis dahin frei beweglichen Hoden wurden fixiert und hinderten durch ihre starke Volumszunahme das Tier beim Laufen. Nach drei Wochen waren auf der bis dahin glatten Oberfläche des Hodens durch die Haut kleinste bis stecknadelkopfgroße Höckerchen zu tasten. Wir exstirpierten am 24. Tage den Inhalt einer Skrotalhälfte nach Unterbindung des Samenstranges. Die Hüllen des vas deferens, des Hodens und Nebenhodens stark verdickt, infiltriert, miteinander verwachsen. Am Durchschnitte präsentiert sich das noch unveränderte Parenchym des Hodens und Nebenhodens in eine Schale entzïndlichen Granulationsgewebes eingebettet. Entsprechend den eben erwähnten kleinen Prominenzen findet man umschriebene Herde, die in ihrem Inneren eine eitrige nekrotische Masse enthalten. Dieser ganze Prozeß wäre wohl am besten als proliferierende und nekrotisierende Periorchitis zu bezeichnen. Mikroskopisch zeigen diese periorchitischen Granulome einen ganz analogen Aufbau wie die Sporotrich ome des Menschen: In der Peripherie Bindegewebe, hierauf eine aus Plasmazellen, epithelioiden und Riesenzellen bestehende Zone. In diesem Zellkomplexe sind zahlreiche kleinere und größere, polynukleäre Leukocyten enthaltende Mikroabszesse zu sehen.

In den Spirotrichomen der Ratte gelingt es leicht, den spezifischen Erreger sowohl im Deckglaspräparate als auch im Schnitte zur Ansicht zu bringen; die "Formes globuleuses" sind kugelige, ovale oder spindelförmige Gebilde, die massenhaft teils zerstreut, teils zu Haufen geballt in dem pathologisch veränderten Gewebe liegen. Sie sind grampositiv und besitzen mitunter eine helle ungefärbte Membran (Kapsel?). 
Bei längerer Nachbehandlung mit Anilinxylol geben einzelne Parasiten den Farbstoff wieder ab und bekommen ein granuliertes Aussehen.

Die Retrokultur aus dem Eiter der Rattensporotrichome ergab wieder die typischen Kolonien des Sporotrichon.

Auf Grund der bakteriologischen und serologischen Untersuchungen sowie des Tierexperimentes konnten wir unsere Diagnose präziser fassen: Syphiloide sporotrichotische Hautgummen, teils hämatogen (de Beurmanns Typus 1), teils lymphogen (de Beurmanns Typus 2) entstanden, in allendreistadien-

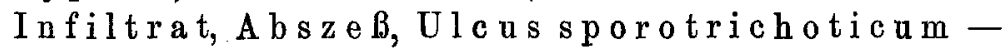
Lymphangtis sporotrichotica des rechten Vorderarmes.

Wir leiteten nun eine energische Jodtherapie ein. Patient erhielt Jodkali intern in steigenden Dosen von $2 \cdot 0$ pro die bis 10.0 pro die. Die offenen stark eiternden Gummen behandelten wir mit Umschlägen einer Jod-Jodkalilösung. Die Eiterung sistierte bald, die nicht perforierten Abszesse involvierten sich rasch und bis zum heutigen Tage ist kein Rezidiv aufgetreten. Die Ulcera sporotrichotica heilen mit einer zarten Narbe ab, die von einem breiten dunkelbraunen Pigmentserum umgeben ist. Trotz der hohen Jodgaben trat kein Jodismus auf.

Abgesehen ron dem klinischen Interesse, welches unser Fall vielleicht bietet, hat er auch eine gewisse epidemiologische Bedeutung. Bis jetzt ist die Sporotrichosis, wenn wir die wenigen amerikanischen Beobachtungen in Abzug bringen, nur in Paris beschrieben worden. Es hatte den Anschein, als ob diese Infektion tatsächlich eine "Modekrankheit" der Franzosen wäre. Durch unseren Fall ist der Beweis geliefert, daß sie auch innerhalb Europas nicht auf Frankreich beschränkt ist; denn unser Patient hat seit 15 Jahren die Schweiz nicht verlassen und sich sicher hier infiziert. Es ist zur Zeit natürlich nicht möglich, irgend etwas darüber auszusagen, ob die Sporotrichosis wirklich in Frankreich soviel häufiger ist als in den anderen europäischen Ländern, oder ob man dort, wo diese Affektion zuerst genauer erforscht wurde, mehr auf sie achtet und sie deshalb so häufig gefunden hat. 
Die Verwechslung mit Lues liegt um so näher, als diese Diagnose ex juvantibus (Jodkali) scheinbar noch gestützt wird. Vielleicht figuriert in mancher Seroreaktionsstatistik eine tertiäre Lues mit negativer Komplementfixation, die sich bei genauer Untersuchung als Sporotrichose entpuppt hätte. Geheilt wird auch die fälschlich als Syphilis diagnostizierte Sporotrichosis durch Jodkali. Aber es ist für den Patienten nicht gleichgültig, ob er das Bewußtsein hat an einer tertiären Lues zu leiden oder an einer, soweit wir wissen, ohne alle Folgen heilbaren Krankheit, wie die Sporotrichosis es ist.

Noch wichtiger ist die Differenzierung gegen Tuberkulose, weil die langwierige, operative oder konservative Therapie der letzteren in Fällen, die zu Unrecht als solche diagnostiziert wurden, tatsächlich aber durch die kulturelle Untersuchung als Sporotrichose aufgedeckt werden könnten, überflüssig ist. Die Kenntnis dieser neuen Krankheit hat also - neben ihrem theoretischen - einen großen praktischen Wert.

\section{Literatur.}

Eine Zusammenfassung der bis zum Jahre 1908 erschienenen englischen und französischen Arbeiten gibt das Sammelreferat H. G. Adamson, Sporotrichosis. The British Journal of Dermatology. Sept. 1908. Bd. XX. Nr. 9.

Die gesamte kasuistische Literatur (ca. 20 Fälle) berücksichtigen:

De Beurmann und Gougerot. Sporotrichosis. Iconographia dermatologica. Fasc. III. 1908.

In vorliegender Arbeit sind zitiert:

De Beurmann und Ramond. Multiple subkutane Abszesse myrotisehen Ursprungs. Annal. d. Derm. et Syph. 1903.

De Beurmann und Gougerot. Die subkutanen Sporotrichosen. Annal. d. Derm. et Syph. 1906.

Dieselben. Annal. d. Derm, et Syph. 1907.

Dieselben. Bull. de la Soc. d. Derm. 1907.

Dieselben. Die Rolle der Jodsalze bei der Sporotrichose. Bull. de la Soc. d. Derm. 1908.

Dieselben. Akute Sporotrichosen. Annal. d. Derm. Bd. X. Febr. 1909.

Dieselben, Ramond und Vaucher. Die Diagnose einer überstandenen Sporotrichose durch Sporen-Agglutination. Ann. d. Derm. 1908. 
Dieselben und Vaucher. Orchitis sporotrichotica der Ratte. Annal. de Derm. 1908.

Dies elben und Va u cher. Sporotrichotische Epididymitis, Orchitis, Vaginalitis. Annal. de Derm. 1908.

Dieselben und Va u cher. Experimentelle Heredo-Sporotrichosis. Bull. de la Soc. med. đ. Hôp. d. Paris. 1908.

De Beurmann, Brodier und Gastou. Hautsporotrichosis mit Läsionen im Larynx. Bull, de Soc. med. des Hôp. d. Paris. 1907.

Brayton. Chronic Abscesses. Indianapolis med. Journal. 1899.

Bd. XVIII. (zit. nach A d a m son).

D or. Sporotrichosis. Presse med. 1906.

Druelle und Chadzinsky. Sporotrichosis mit periostalen Abszessen. Bull. de la Soc. d. Derm. 1908.

Ga ucher und Fouquet. Kerionähnliche Sporotrichosis. Bull. de la Soc. 1908.

Ga ucher, Lous te, Abrami und Giroux. Sporotrichosis (Eosinophilie, Leukocytose, positive Agglutination und Komplementfixation). Bull. de la Soc. 1908. méd. 1908.

Gougerot und Caraven. Sporotrichosis des Hundes. Presse

Hectoen und Perkins. Refractory Subcutaneous abscesses caused by Spor. Schenkii. Journ. of exper. Med. 1900 (zit. nach A d a m s o n). Lesné und Monier-Vinard. Multiple sporotrich. Abszesse. Bull. de la Soc. de Derm. 1906.

Letulle. Sporotrichosis d. Mundschleimhaut. Presse méd. 1908.

Morax. Sporotrichose am Auge. Kongreß der Deutschen ophthalm. Gesellschaft. Heidelberg 1908. Bericht Wiesbaden 1909.

Lutz und Splendore. Zit. nach Adamson.

Schenk. On refractory subcutaneous abscesses caused by a fungus. John. Hopk. Hosp. Bull. 1898.

Sicard and Descamps. Sporotrichosis mit positiver Agglutination. Ann. d. Derm. et Syph. 1908.

Widal und Abrami. Serodiagnose d. Sporotrichose durch Sporenagglutination. Ann. de Derm. 1908.

Widal und Weil. Sporotrichosis mit Haut-, Muskel- und Periostgummen. Parasiten im Blut. Bull. de la Soc. méd. des Hôp. de Paris. 1908.

\section{Erklärung der Abbildungen auf Taf. I-III.}

Zahlreiche Reproduktionen histologischer Präparate von menschlicher Sporotrichose finden wir in den Arbeiten de Beurmanns und Gougerots. Wir verzichten daher auf Wiedergabe unserer Schnitte.

Taf. I:

Moulage des rechten Vorderarmes (teils spontan perforierte, teils inzidierte Sporotrichome, Lymphangitis sporotrichotica). 


\section{T af. II :}

1. Drei Wochen alte Kolonien des Sporotrichon aus dem Abszeßeiter auf Maltoseagar gezüchtet.

2. Vier Wochen alte, noch weibe Pilzkolonie, aus dem Abszeßeiter auf Traubenzuckeragar gezüchtet.

3. Vier Wochen alte schwarze Pilzkolonie aus dem Abszeßeiter auf Maltoseagar gezüchtet.

4. Sechs Wochen alter sehwarzer Pilzrasen auf Maltoseagar (II. Generation).

5. Sechs Wochen alter schwarzer Pilzrasen mit weißem flaumigen Saume auf Glyzerinkartoffel (II. Generation).

Sämtliche Kulturen bei Zimmertemperatur gehalten.

Taf. III:

1. Sporentragende Pilzfäden aus einer 21 Tage alten GlykoseBonillonkultur. (Vergr.: Zeiß Oc. 4. Obj. DD. Färbung: Bismarckbraun.)

2. Sporotrichom des Rattenhodens, nach Gram - Weiger t gefärbt. Im Granulationsgewebe zerstreut die formes globuleuses des Parasiten, stellenweise in dichten Haufen bei einander liegend. (Vergr. Zeiß. Oc. 4. Obj. DD.) 




Robert Stein: Sporotrichosis etc. 


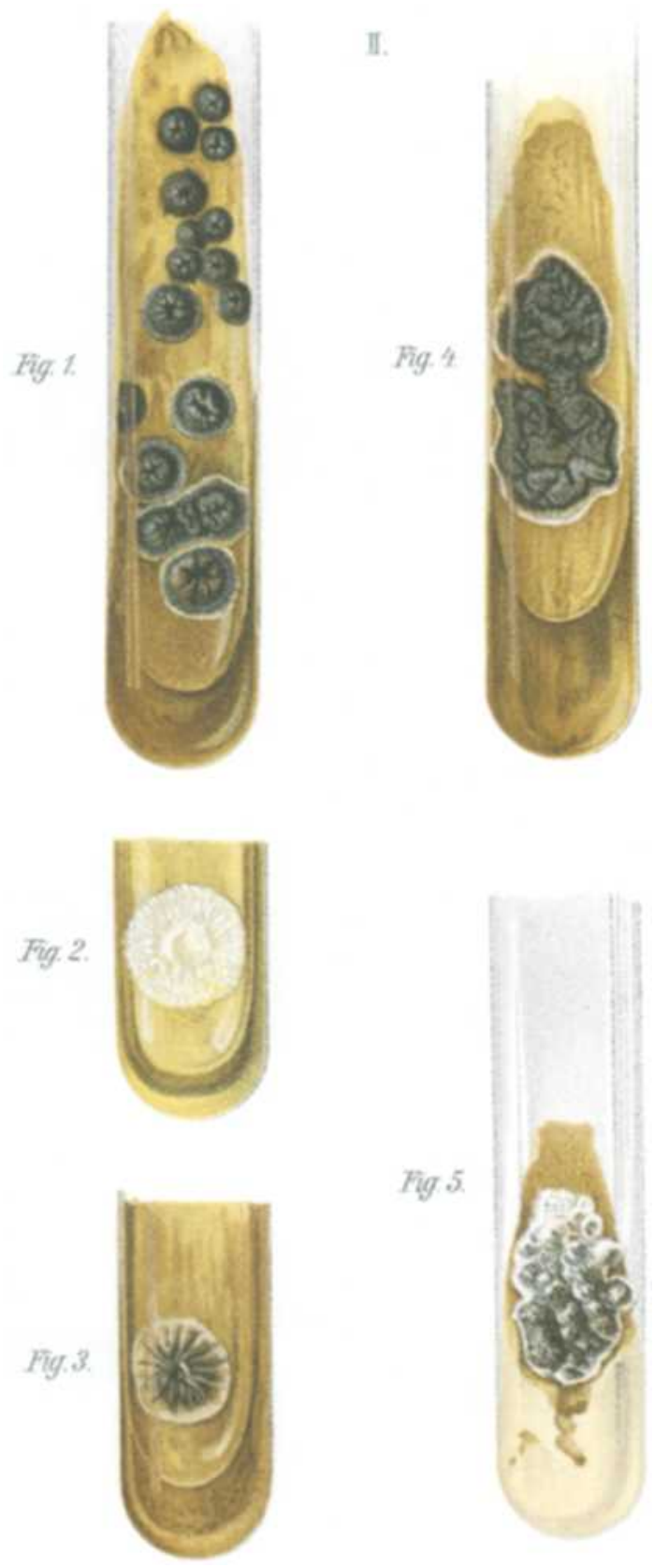

Robert Stein: Sporotrichosis ete. 

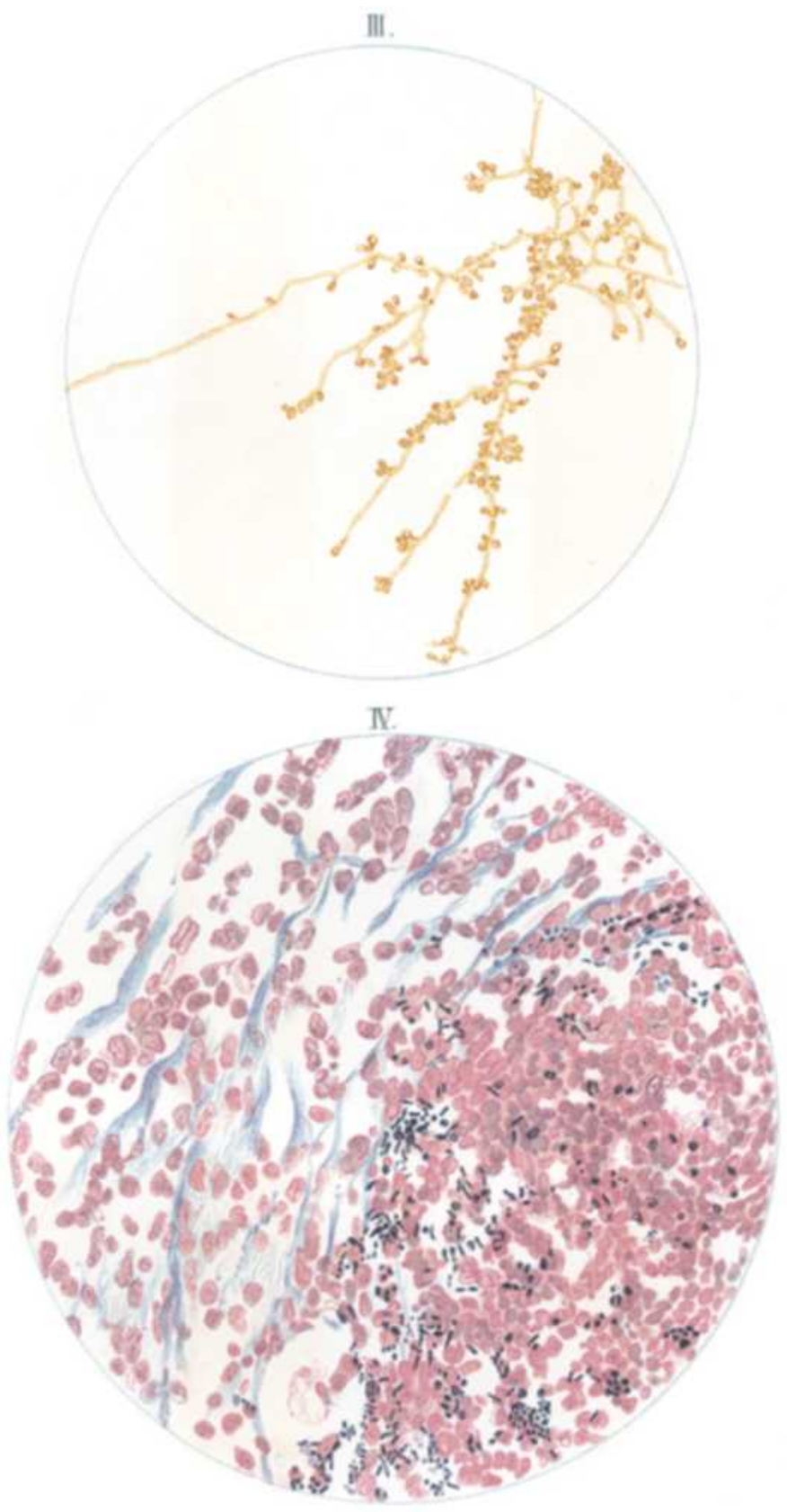